\title{
Intervención arqueológica en la Puerta de Baeza. Nuevas aportaciones al sistema fortificado de la ciudad de Jaén
}

\author{
Mercedes Navarro Pérez * \\ Vicente Barba Colmenero * \\ Francisca Alcalá Lirio * \\ Francisco Arias de Haro *
}

\section{INTRODUCCIÓN Y CONTEXTO}

Durante los primeros meses del año 2003, se realizó una Intervención Arqueológica I encuadrada dentro de las obras de remodelación de la Plaza Doctor Blanco Nájera, tradicionalmente denominada Plaza de los Huérfanos (Figura $n^{\circ}$ I). Esta actuación, se llevó a cabo dentro del ámbito del Proyecto Urban (Ayuntamiento de Jaén), que viene desarrollándose en el casco histórico, a través de remodelaciones en los distintos espacios públicos de la ciudad de Jaén.

La excavación arqueológica consiguió documentar parte del sistema de fortificación de la ciudad medieval, que atravesaba la plaza procedente de la medianería trasera de las viviendas de la calle Millán de Priego, y dirigiéndose hacia la Plaza de los Jardinillos (Lámina $n^{\circ}$ I). También se localizó de una de las puertas de entrada a la ciudad: la Puerta de Baeza.
Esta plaza se convierte en el punto de unión en el que convergen las calles de San Andrés, los Huérfanos y las Huertas, desembocando todas en la Calle Millán de Priego. Las tres primeras, angostas y estrechas, conservan aún la antigua trama urbana, donde en siglos anteriores residían familias nobles y adineradas. Hoy se puede observar que estas calles forman parte de un barrio excluido, donde la pobreza y la marginalidad adquieren su mayor protagonismo. La plaza hace de punto de unión entre el antiguo y el nuevo Jaén; y la calle Millán de Priego y sus alrededores, se han convertido en los últimos años en un ir y venir de gentes que acuden a sus numerosos comercios y establecimientos de ocio, y donde el tránsito de vehículos y personas es constante.

De esta forma, la Plaza de los Huérfanos se ha convertido en la unión sui géneris entre dos formas distintas de vida, el silencio y el bullicio, la pobreza y el consumismo; del mismo modo,

* Arqueólogos

I Francisco Arias de Haro, Mercedes Navarro Pérez, Francisca Alcalá Lirio y Vicente Barba Colmenero: "Intervención Arqueológica de Urgencia en la Plaza Dr. Blanco NájeralLos Huérfanos, de Jaén" (2003). 
que en otros tiempos este mismo espacio unía la vida intramuros y extramuros, la ciudad y el campo.

La morfología del espacio es irregular, sin sufrir demasiados cambios desde la demolición de la muralla y la puerta. Sin embargo, en los últimos cuarenta años las antiguas casas que configuraban el entorno de la plaza, como es el caso del viejo palacio perteneciente al Caballero Veinticuatro Don Tomás de Vera y Prado, el cual cedió en 1696 para casa de niños huérfanos y que dio nombre a la calle y la plaza; han sido sistemáticamente demolidas para la construcción de bloques de pisos que han borrado su antigua traza y fisonomía.

La existencia de la plaza es relativamente moderna, en 1887 la muralla y la puerta ya habían desaparecido, adquiriendo el lugar una topografía similar a la que conocemos actualmente. En el transcurso de la intervención arqueológica aparecieron restos de los antiguos empedrados pertenecientes a distintos momentos constructivos del espacio público. También se ha documentado un refugio antiaéreo de la Guerra Civil Española, construido en 1939, y al que no pudimos acceder a través de su largo pasillo abovedado por encontrarse totalmente hundido y colmatado su interior.

\section{LA INTERVENCIÓN ARQUEOLÓGICA}

Durante el proceso de excavación se realizaron cuatro sondeos, los cuales se ubicaron en aquellas zonas donde las obras de remodelación de la plaza iban a afectar al subsuelo, por la colocación de diversas infraestructuras urbanas (Figura $n^{\circ} 2$ ). Hay que señalar que nos encontrábamos en un espacio público donde el transito de vehículos y personas era constante, motivo por el cual la intervención ha estado sujeta a continuas modificaciones y planteamientos metodológicos.

El primer sondeo realizado tenía unas dimensiones de 4 por 2.5 metros, y fue ubicado en el extremo Sur de la plaza. Se documentaron básicamente elementos de equipamiento urbano contemporáneos: canalizaciones, zanjas de cableado, saneamientos, etc. No hemos podido llegar a alcanzar la base geológica debido a que una gran atarjea atravesaba el corte y aún se encontraba en funcionamiento. Los estratos arqueológicos registrados demuestran que nos encontramos a intramuros de la ciudad medieval, ya que su topografía horizontalizada parece indicar que van a chocar contra la muralla que actuaría como contención de ellos, y nos aportan materiales medievales tanto castellanos como islámicos. De no ser así, los estratos presentarían una acusada pendiente descendiente hacia la calle Millán de Priego, ya que al exterior de la ciudad se localiza un gran barranco, y si es correcto un foso defensivo (ver Arias, Alcalá, Barba y Navarro en este mismo volumen).

El siguiente sondeo que se realizó tenía unas dimensiones de 9.5 por 2.5 metros, y quedaba situado al suroeste de nuestro ámbito de estudio, lugar donde, como ya hemos indicado, se localizó un refugio antiaéreo de la Guerra Civil Española.

El tercero de ellos se ubicó al Noroeste, en el límite de la plaza con la calle San Andrés. En un principio se planteó con unas dimensiones de 10 por 2.5 metros, pero debido a que el lugar estaba ocupado por equipamientos urbanos en uso: cables de alta tensión, de televisión y tuberías de gas; se tuvo que reducir a I.30 por 8 metros. En él se localizó la antigua alineación de fachadas de las casas medievales en la calle San Andrés para época moderna.

El último sondeo se realizó en el centro de la plaza, en un principio presentaba unas dimensiones de 8 por 4 metros, aunque sucesivamente fue ampliándose por localizarse las estructuras del sistema de fortificación medieval y la puerta de entrada a la cuidad. Los elementos documentados que forman parte de este sistema son: lienzos de murallas con diversas fases constructivas, una torre y la puerta de acceso; formando parte todos ellos del conjunto defensivo de las murallas medievales de la zona sureste de la ciudad. 


\section{RESTOS ARQUEOLÓGICOS DEL PERÍODO ISLÁMICO}

Para la fase califal no se ha documentado ningún elemento perteneciente al sistema de fortificación que hemos encontrado; sin embargo, se han localizado varias estructuras realizadas con mampostería irregular y un suelo de ocupación, cuya funcionalidad es difícil de precisar, ya que nos aportan datos muy parciales, debido a las reducidas dimensiones que ocupan y principalmente, a la construcción de la fortificación en una fase posterior en este mismo lugar, lo cual originó una gran remodelación del espacio arqueológico anterior. Hay que decir, que se trata de varios muros y un pavimento formado por losas de mármol blanco (Lámina $n^{\circ}$ 2). Se encontraban amortizados por un relleno con material cerámico de época omeya, y bajo el pavimento apareció un pequeño estrato de tierra compacta sobre la base geológica, a modo de nivelación intencionada del terreno, que también nos aportaba cultura material correspondiente a los siglos IX-X, lo cual nos indica que la estructura tuvo una pervivencia muy reducida.

En esta época, si es correcto, la fortificación de la ciudad se situaba más retranqueada, por donde se supone que discurre la cerca romana ${ }^{2}$, aunque se desconoce su ubicación exacta por el momento, por lo que estos restos encontrados debían emplazarse a extramuros. Lo cual nos sugiere que se corresponden con algún tipo de edificio relevante, y el pavimento de mármol pertenecería a una al-munya cercana a la ciudad, dado que esta clase de suelos no son habituales en viviendas corrientes, siendo muy posible que fuera de un alto cargo mandatario o de un miembro aristocrático.

De época Almohade se corresponden varias estructuras anteriores a la construcción de la fortificación de la ciudad. Encontramos una canalización excavada en el sustrato geológico, y una fosa igualmente subterránea de tipo vertedero, en cuyo interior se pudo recuperar materiales relacionados con la producción cerámica de esta época: gran cantidad de atifles y rollos de barro utilizados en hornos a modo de parrilla.

En un momento posterior, comprendido entre los siglos XI-XII, se construyen las principales estructuras documentadas y relacionadas con la fortificación islámica: lienzos de murallas que reproducen un trazado zigzagueante en todo el recorrido de la plaza, y adosada a ella una torre que con toda seguridad defendía un acceso en esta parte de la ciudad islámica. No ha sido posible documentar la estructura de la puerta de esta época, aunque creemos que se encontraría en el mismo lugar que la perteneciente al período castellano, como veremos, en uno de los quiebros de la muralla y resguardada por varias torres (Figura $n^{\circ} 3$ ).

La muralla almohade se apoya directamente sobre la base geológica, adaptándose perfectamente a la propia topografía del terreno y en otros casos sobre niveles arqueológicos anteriores (estructuras y pavimento de época califal). Separa un gran desnivel entre el interior de la ciudad y el exterior, conservándose un alzado de 1.70 metros hacia dentro y a extramuros unos 3 metros de profundidad. Si tenemos en cuenta que actualmente las estructuras documentadas están demolidas, podríamos suponer una altura original al exterior de al menos 8 metros.

Los restos de muralla documentados marcan la siguiente trayectoria (Figura $n^{\circ} 3$ ): dirigiéndose hacia la plaza desde el edificio "Veredas" (CASTILLO, PÉREZ, MARÍN y ZAFRA, 1995),

2 Aunque también se desconoce con exactitud el recorrido de la fortificación romana, que solamente ha sido documentada dentro del ámbito urbano en la calle Borja (J. Zafra: "Intervención Arqueológica en el solar de la calle Borja, $n^{\circ} 6$ de Jaén"). Si los estudios son ciertos, el recorrido lo realizaría cerca de nuestra excavación, por la calle San Andrés atravesando un lateral de la Plaza de San Juan. Excavaciones arqueológicas recientes realizadas en esta plaza y alrededores ha conseguido delimitar una necrópolis visigoda con enterramientos que perduran hasta época Emiral (M. Navarro, V. Barba y F. Alcalá: "Intervención Arqueológica de Urgencia en la Plaza de San Juan" 2003), y estructuras de época califal a escasos 50 metros hacia donde se supone que se encuentra el interior de la ciudad (F. Arias, M. Navarro, F. Alcalá y V. Barba: "Intervención Arqueológica en la calle Vacas de San Juan, n I I"), por lo que debe ubicarse en ese ámbito. 
desciende desde el inicio de la calle San Andrés con dirección Este, produciéndose un primer quiebro hacia la parte central de la plaza con trayectoria Sureste. Este primer tramo conserva una longitud de unos 10 metros aproximadamente. Existe un nuevo quiebro, aunque de poca entidad, hacia el Sur, marcándonos un nuevo tramo de 5 metros de longitud y una anchura de 3 metros, coincidiendo con el lugar donde se adosa la torre excavada (Lámina $\mathrm{n}^{\circ}$ 3). El último trayecto documentado de esta estructura defensiva, se corresponde con un nuevo giro con dirección hacia el Este, tramo donde se aprecian las mayores reformas de época castellana y donde se localiza la puerta de acceso a la ciudad.

La muralla almohade se construye de tabiyya, mediante cajones de encofrado que han dejado la huella de los mechinales, espaciados regularmente en líneas horizontales a una distancia de 1.60 metros (Lámina $n^{\circ}$ 4). Presenta sucesivas reparaciones en época medieval cristiana, localizándose pequeños arreglos de esquinas y reparcheos en las caras, apreciables por la utilización de distintos tipos de argamasa y la incorporación, en algunas zonas, de sillares. Aunque la muralla islámica no presenta "encamisados" de sillares como en otras partes del recinto fortificado (ver distintos artículos en este volumen), ello es debido a que pudo ser uno de los puntos más fuertes y mejor conservados, tal y como lo apunta S. Lázaro, al indicar que en la documentación que ha consultado no se registran reparaciones posteriores, y de haberlas serían de poca importancia (S. LÁZARO, 1988: 36).

La torre documentada durante la intervención arqueológica se sitúa al nordeste adosándose a la muralla. Apoyada sobre la base geológica mantiene la misma técnica constructiva que la muralla, mediante cajones de tapial, conservando un alzado de 3 metros (Figura $n^{\circ} 4$ ). A falta de confirmar la situación exacta de su cara Norte, se prevé que tenga unas dimensiones de 4 metros en sus dos laterales y de 5 en su cara frontal. En su interior se ha documentado un suelo de ocupación que nos confirma que la torre tendría una sala inferior de una sola estancia, cuyo acceso se realizaría desde el adarve de la muralla para época islámica, aunque para el momento castellano, como veremos, la sala que presenta esta torre se encuentra totalmente amortizada.

En la zona de intramuros, junto a la muraIla, se consiguió delimitar un suelo empedrado con sucesivas nivelaciones, que anula estructuras anteriores como la fosa y la canalización descrita, y que en parte se apoya sobre la base geológica. Se corresponde con una calle que discurría paralela a la muralla y se encontraba demarcada por un muro perteneciente a una vivienda de época almohade, delimitándose un camino de ronda de 4 metros de anchura. La calle es continuamente recrecida entre los siglo XI-XIII, por sucesivas nivelaciones de distintos suelos empedrados bajo los cuales se han localizado atarjeas, cuya función es la evacuación de aguas residuales del interior de la ciudad islámica (Figura $n^{\circ} 5$ ). Todas ellas presentan inclinaciones descendentes hacia el Norte de la plaza, por lo que debe de existir algún tipo de desagüe en este tramo de la muralla.

\section{RESTOS ARQUEOLÓGICOS DEL PERÍODO CRISTIANO}

Tras la conquista castellana se observan importantes reformas que en el sistema de fortificación de la ciudad medieval, aunque, como ya hemos apuntado, en nuestro ámbito son de poca importancia. En el extremo sur y donde la muralla realiza un quiebro hacia la calle Millán de Priego, se produce la reforma más destacada: la construcción de una nueva puerta de entrada a la ciudad, que daba acceso directo al barrio de la judería (SALVATIERRA, V. 2003). Para ello, y como hemos dicho, pensamos que es muy posible que se reproduzca la estructura de una puerta anterior, la cual se encontraba en un proceso paulatino de deteriorado tras la conquista (Lámina $n^{\circ}$ 5). Se reparan los antiguos lienzos de tabiyya localizados junto a la misma, para lo cual se levanta un muro de sillares unidos con argamasa, reforzando la estructura de la puerta, la cual presenta unas dimensiones de 3 metros de ancho, por el grosor que tiene la propia muralla que es también de 3 metros (Figura $n^{\circ}$ 6). Se encuentra apo- 
yada directamente sobre la muralla islámica, y se pudieron documentar algunos herrajes como un molinillo y la quicialera de la puerta (Figura $n^{\circ}$ 7). También se localizaron elementos reutilizados como es el caso de una columna de mármol, que hacía la función de tope de la puerta en su cara exterior, y que se encontraba pulida por acción del paso de los carros. Esta entrada esta orientada a la actual calle Huérfanos, y se encontraba protegida por la torre anteriormente descrita.

Pensamos que esta torre se correspondería con la identificada en los documentos estu-

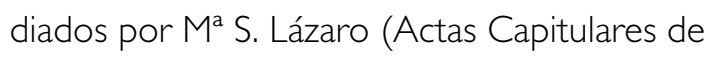
1695), que se describe como "una torre que miraba a la puerta Vaeza mas de seis varas fuera del arco" (LÁZARO MaS., 1988: 36). Queda ubicada de frente a la puerta y distanciada de ella a 6.5 metros, de tal forma que la Puerta de Baeza, junto al quiebro que realiza la línea de fortificación en este lugar, queda totalmente protegida. La torre es este período no presenta ninguna sala inferior, ya que se encontraba rellena por materiales y escombros de época islámica.

El Deán Mazas describe la Puerta de Baeza como si de un acertijo se tratara: "son dos puertas en una dispuestas de modo que ninguna se descubre de frente", a lo que varios autores han resuelto que se trata de una puerta en recodo. Nosotros no hemos identificado ese doble codo, pese a que durante la intervención arqueológica se buscó, y pensamos que más bien lo que nos quiere decir es que la propia puerta, dada la anchura que presenta, tiene dos entradas: un pequeño postillo por donde pasan las personas, y otra entrada más grande por donde circulan las bestias y los vehículos (dos puertas en una). La columna anteriormente descrita hace de separación entre ambas, de esta forma se realizaría un control más exhaustivo de las personas y las mercancías que entraban y salían de la ciudad, y fue este dato el que llamó la atención al Deán Mazas.

Se sabe que contaba con arcos de ladrillo, y S. Lázaro apunta que quedaba flanqueada por dos torres almenadas, de una de ellas no hemos encontrado restos, posiblemente fue destruida cuando realizaron el edificio contiguo, la otra torre es la identificada en la excavación.

Existe un grabado realizado en 1567 por Vanden Wyngaerde, en el cual se nos muestra una panorámica de la ciudad medieval con el sistema de fortificación. En él se puede observar el trazado de la muralla y las diferentes puertas que en ella había. La Puerta de Baeza no aparece reflejada en el grabado, el motivo podría ser que la puerta por su disposición queda totalmente oculta desde la panorámica de donde autor realiza el dibujo (aproximadamente en el extremo sur de la Zona Arqueológica de Marroquíes Bajos). Nosotros mismos hemos buscado esa perspectiva del dibujo sobre el terreno, y efectivamente, aunque hoy en día se complica más la visión de la ciudad por los edificios, no quedaba reflejada por que se encontraba escondida por las torres que la protegían.

Observando el grabado (Figura $n^{\circ} 8$ ), la Puerta de Baeza se localizaría en el tramo de la muralla existente entre la Puerta de San Agustín (I), que se encontraba situada en la actual Plaza de los Jardinillos y la Puerta del Sol, junto al Pilar del Arrabalero. La muralla discurre a lo largo de la actual calle Millán de Priego en dirección noroeste. En el dibujo, aunque las distancias reflejadas parecen ser bastante relativas, se observa la existencia de cuatro torres entre ambas puertas, y alguna de ellas podríamos identificarlas con las documentadas durante las tareas de demolición e intervenciones arqueológicas realizadas en las últimas décadas.

Juan Eslava Galán (1999) hace referencia a la demolición, frente al nacimiento de la calle Castilla de un lienzo de muro de $11.60 \mathrm{~m}$. de largo y su correspondiente torreón (2). La siguiente torre a la que tendríamos que hacer referencia (3) se encontraría entorno a la Puerta Baeza, aunque no existe documentación alguna que nos permita situarla con una localización exacta. A partir de ésta, es posible apreciar en el grabado un cambio en la trama de la muralla, que podría indicarnos cierta profundidad. En este lienzo se localizaría la torre documentada durante la intervención arqueológica 
(4), y que cumpliría una función defensiva respecto a la puerta. Nuevamente, aunque con mayor claridad, es posible apreciar que la muralla realiza un quiebro (documentado durante esta intervención arqueológica). En este lienzo se sitúa una nueva torre (5) localizada en la intervención arqueológica realizada en 199| en el actual "Edificio Veredas" (CASTILLO, PÉREZ, MARÍN y ZAFRA, 1995). Por tanto, la puerta quedaba protegida entre dos torreones en un importante quiebro que realizaba la línea de fortificación (Figura $n^{\circ}$ 9).

En el siglo XVII, en el año 1699, según las fuentes recogidas por S. Lázaro (1988) se realizó una nueva puerta "en lo bajo de la calle San Andrés que es por donde todos se mandan". Referente a ella J.Ureña Castro (1986) publicó un artículo en la revista Senda de los Huertos, en el que proporciona una valiosa documentación gráfica, gracias a la cual podemos saber cómo era y su localización exacta, así como el trazado de la muralla en esta zona (Láminas $n^{\circ} 6$ y 7$)^{3}$. En estos momentos las murallas comenzaban a perder su sentido defensivo, pero ahora adquieren un nuevo protagonismo para defender la ciudad contra las distintas epidemias y plagas. La ciudad de nuevo se aísla para evitar contagios, y la construcción de una puerta en este lugar coincide con un roto importante de las murallas, y que es lugar por donde todos pasan, lo cual suponía un riesgo, regularizándose esta situación evitando la intrusión de personas contagiadas. Esta puerta daría acceso directo a la Calle San Andrés, la cual conserva una trama urbana que podemos rastrear al menos hasta el siglo XVI, aunque sufriendo un ensanchamiento en su trazado para adecuarlo a las nuevas exigencias urbanísticas de los años 80.
La continua ocupación del espacio intramuros se constata ya que una vez construidas las defensas de la ciudad en época islámica y perdurando hasta el siglo XVIII, se superponen atarjeas distribuyendo el agua existente a intramuros hacia el exterior, dirigiéndola a las abundantes huertas que se encontraban en los alrededores. En lo que respecta al caserío, hemos documentado varias estructuras cercanas a las murallas que siguen reproduciendo el camino de ronda que perdura, hasta que en el siglo XIX se decide realizar la plaza demoliéndose todas las estructuras.

Hoy en día, la plaza de los Huérfanos, de nuevo se encuentra en proceso de cambio, el nuevo espacio público contará con la integración de los restos arqueológicos; un nuevo capítulo de la historia de la Puerta de Baeza se está escribiendo.

\section{BIBLIOGRAFÍA}

CASTILLO J.L., PÉREZ M.C., MARÍN, M.M. y ZAFRA, J. (1995): "Intervención Arqueológica de Urgencia en el solar sito entre las calles Millán de Priego, Hornos Franco, Rey Don Pedro y San Andrés de Jaén" A.A.A. III, I 992 Sevilla, 396406.

ESLAVA GALÁN, J. (1999): Castillos y Atalayas del Reino de Jaén. Ideal y La General. Caja de Granada.

LÁZARO DAMAS, S. (1988): Desarrollo histórico del casco urbano de Jaén hasta 1600. Jaén, Colegio Oficial de Aparejadores y Arquitectos Técnicos.

SALVATIERRA CUENCA, V. (2003): "La judería de Jaén. Introducción a su análisis urbano". Boletín del Instituto de Estudios Giennenses, n 185 (Extraordinario), 421-458.

UREÑA CASTRO, J. (1986): "Aparición de restos de construcción de la antigua muralla de Jaén". Senda de los Huertos, 2, 33-34.

\footnotetext{
3 Debido a problemas técnicos con el artículo, J. Ureña no pudo publicar ninguna fotografía sobre esa puerta, aunque sí un croquis bastante exacto de su ubicación. Gracias a la amabilidad de este señor, hemos tenido acceso a esas fotografías para poder comprender mejor la estructura de la puerta.
} 


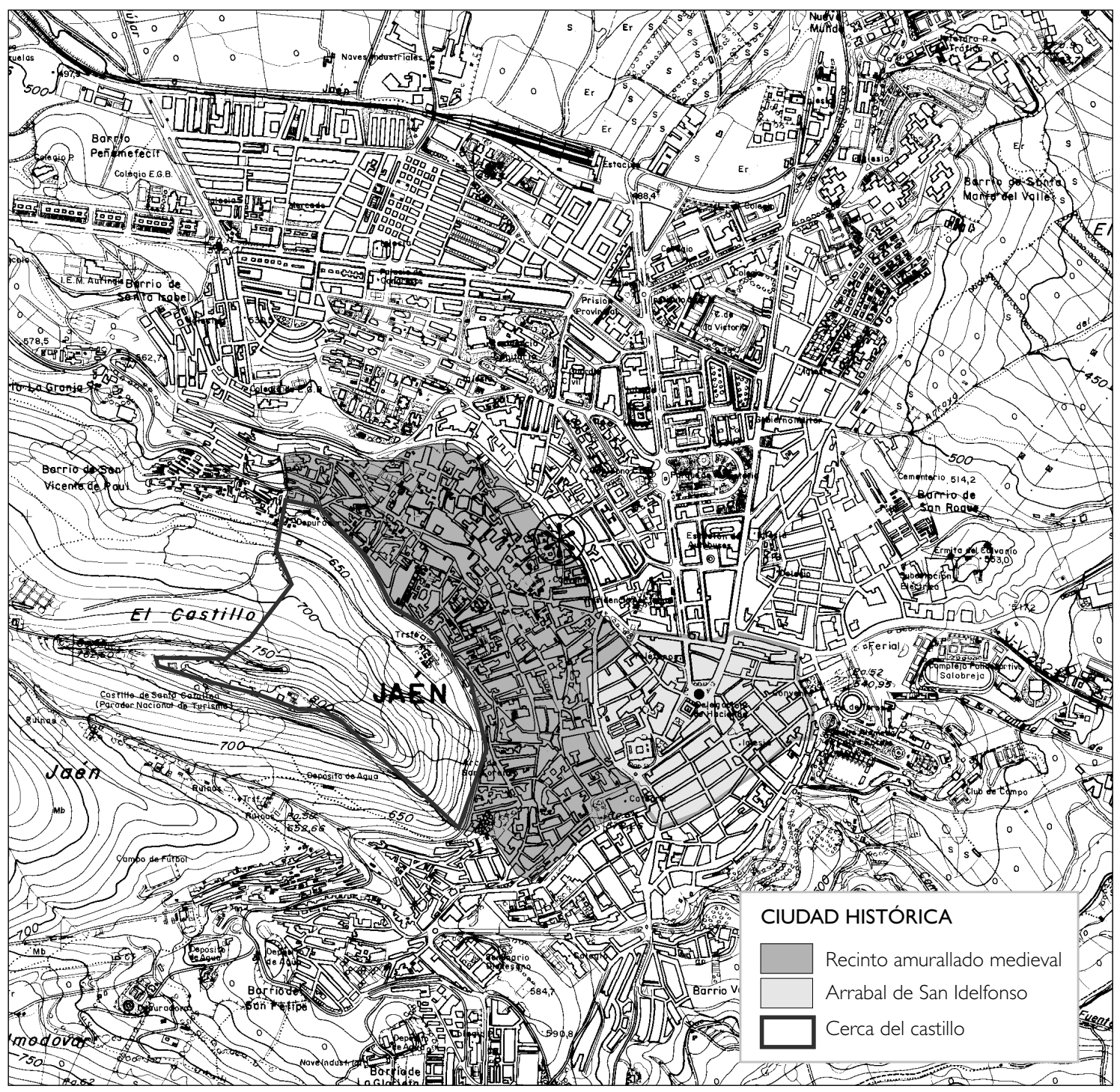

Figura I. Plano de situación de la plaza. 


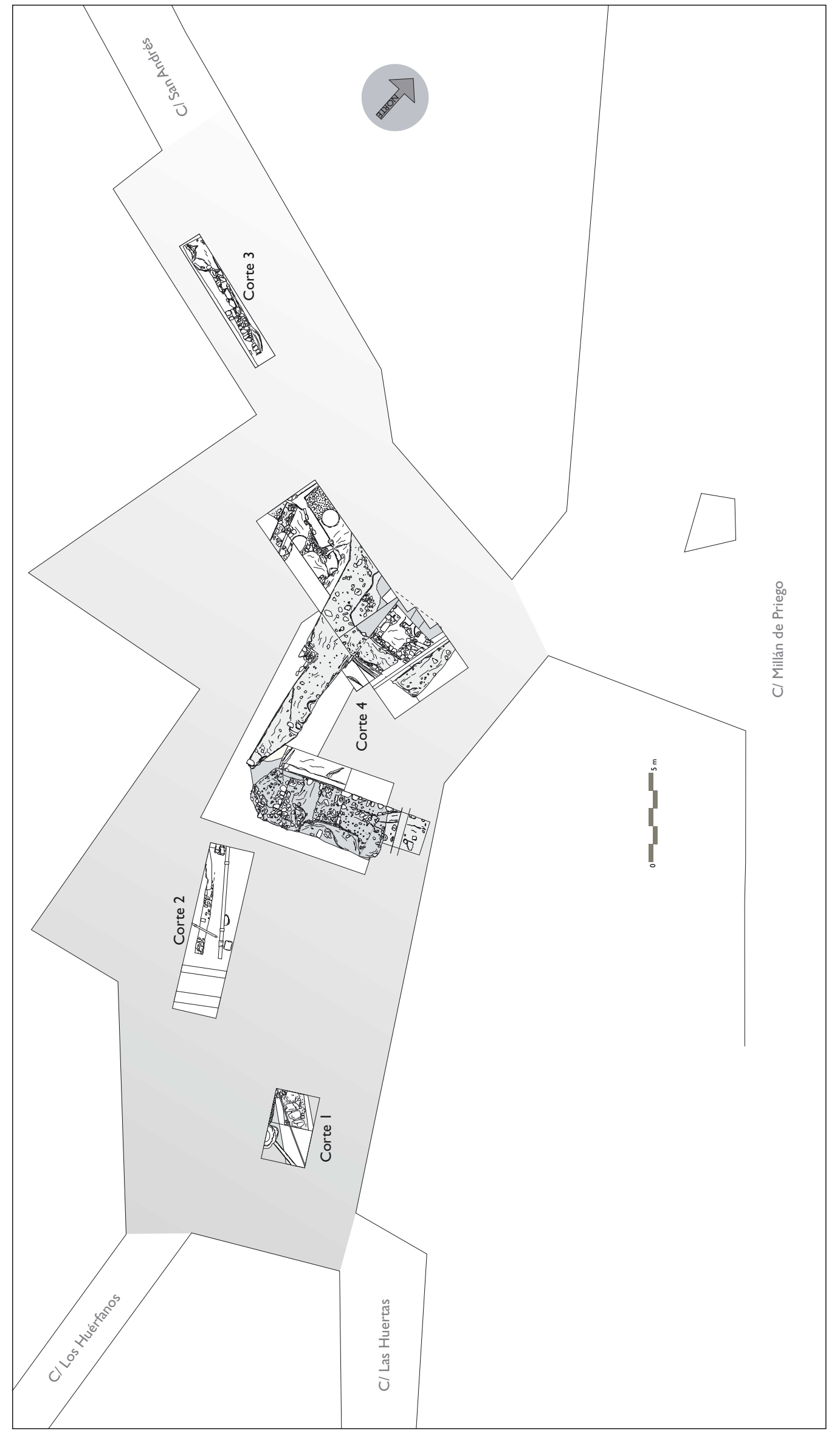




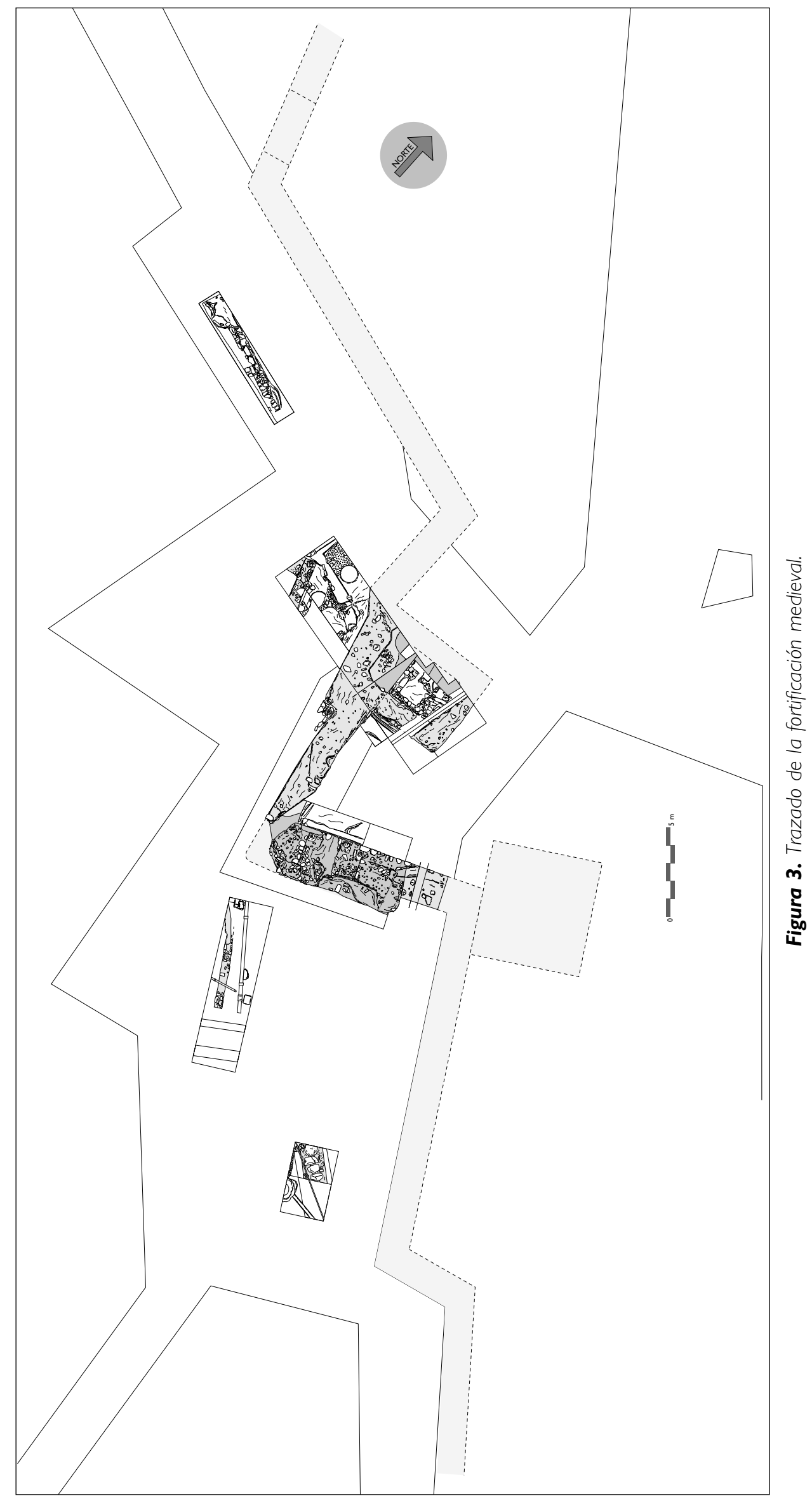




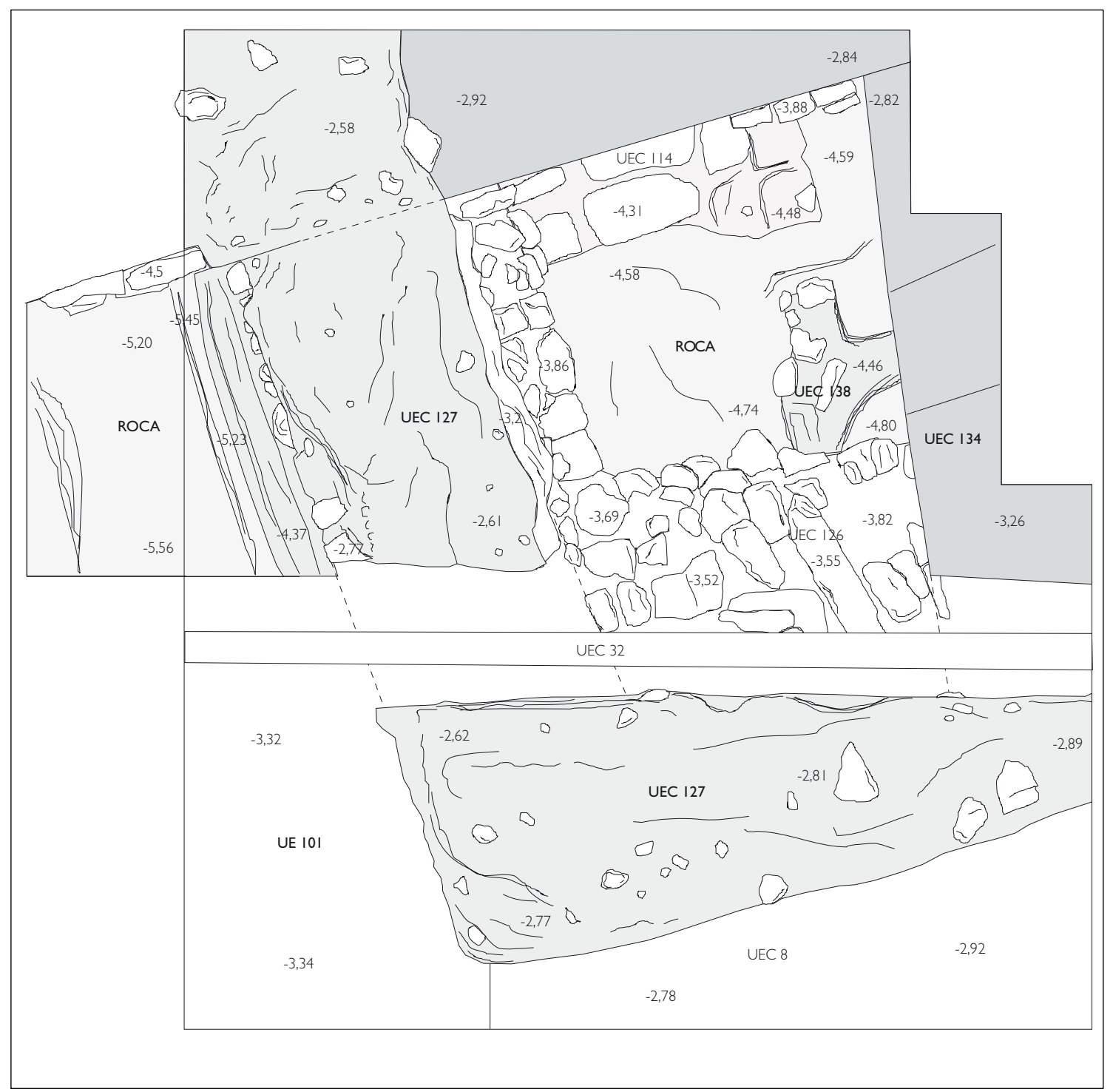

Figura 4. Planta de la torre excavada. 


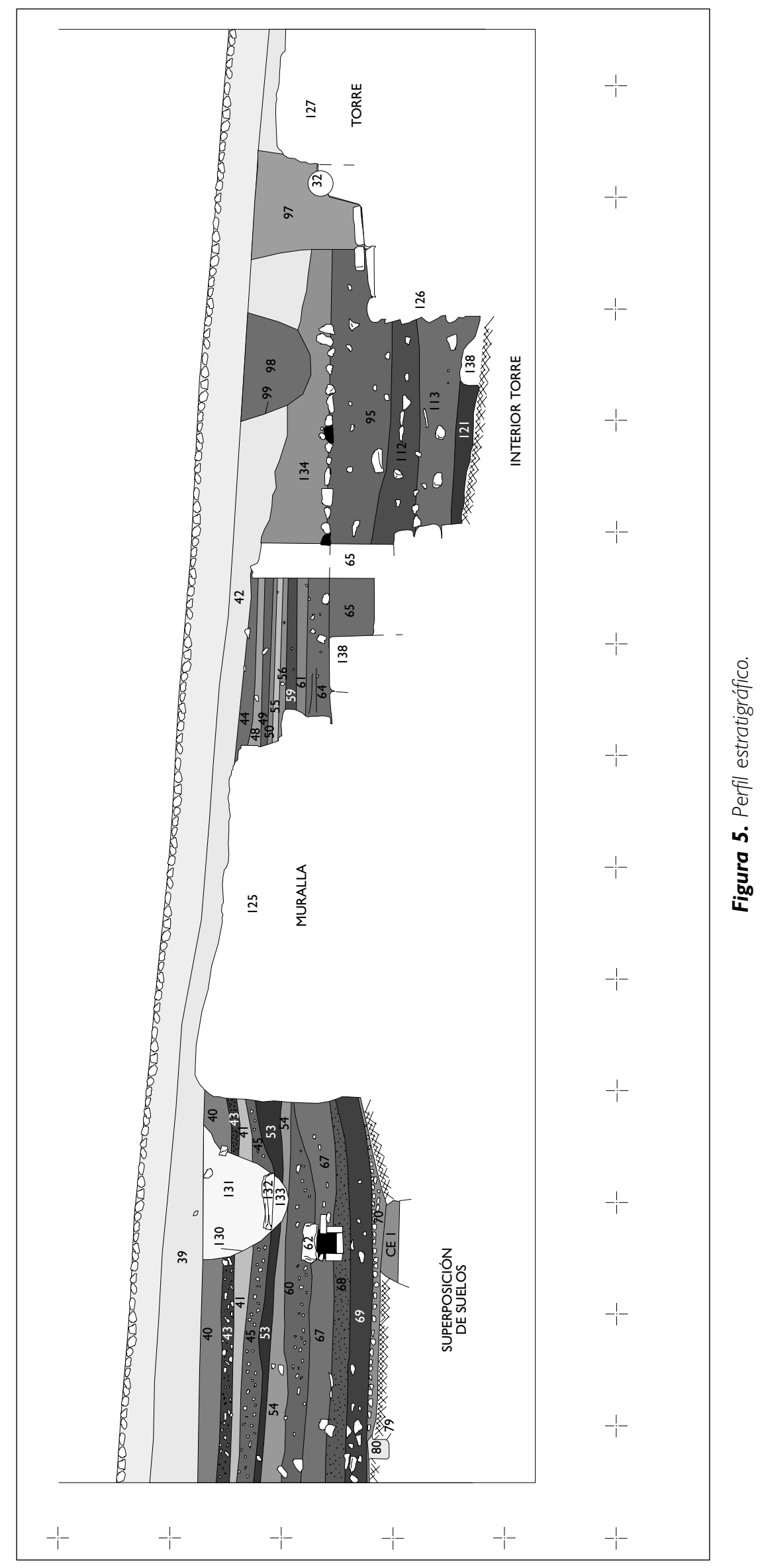




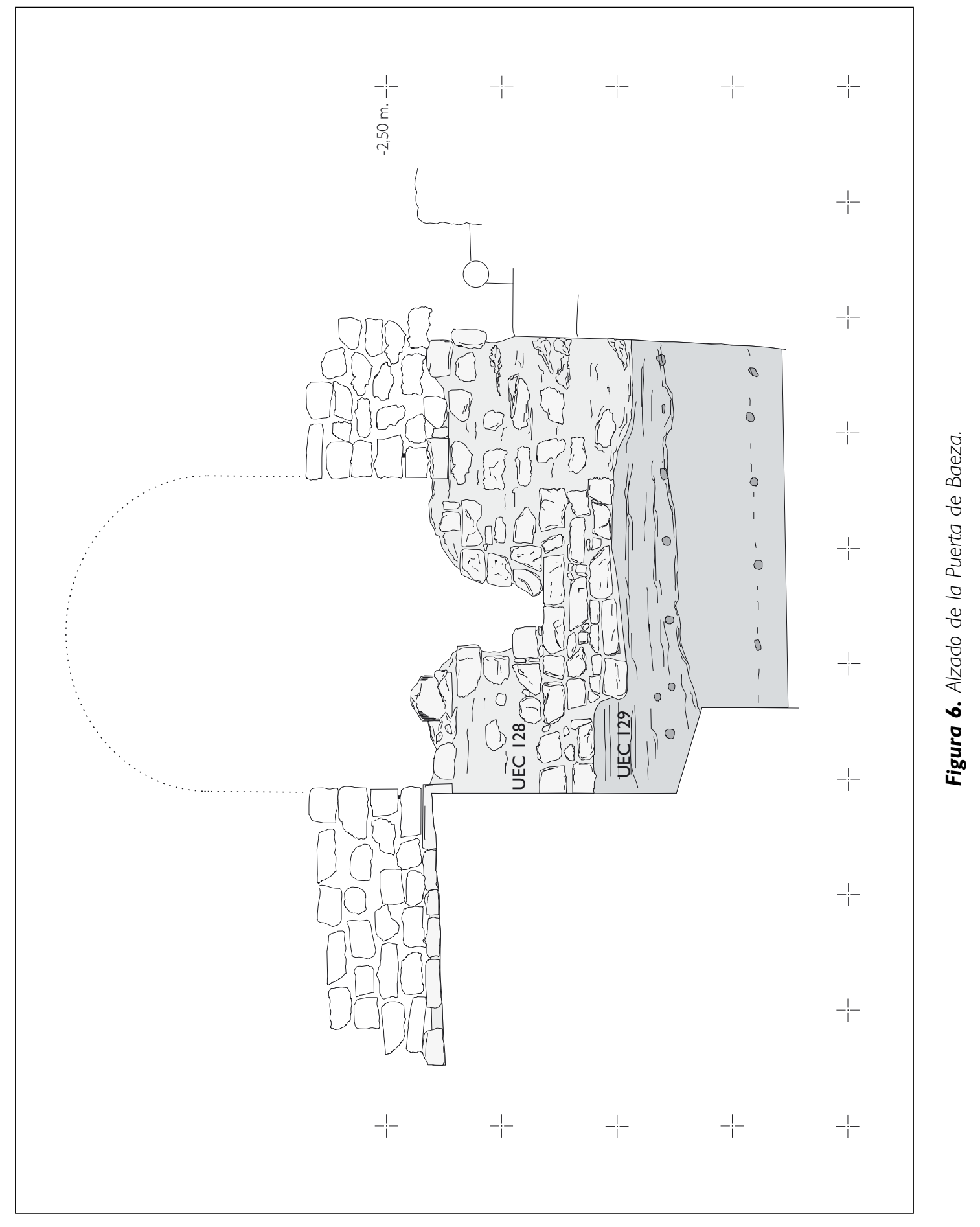




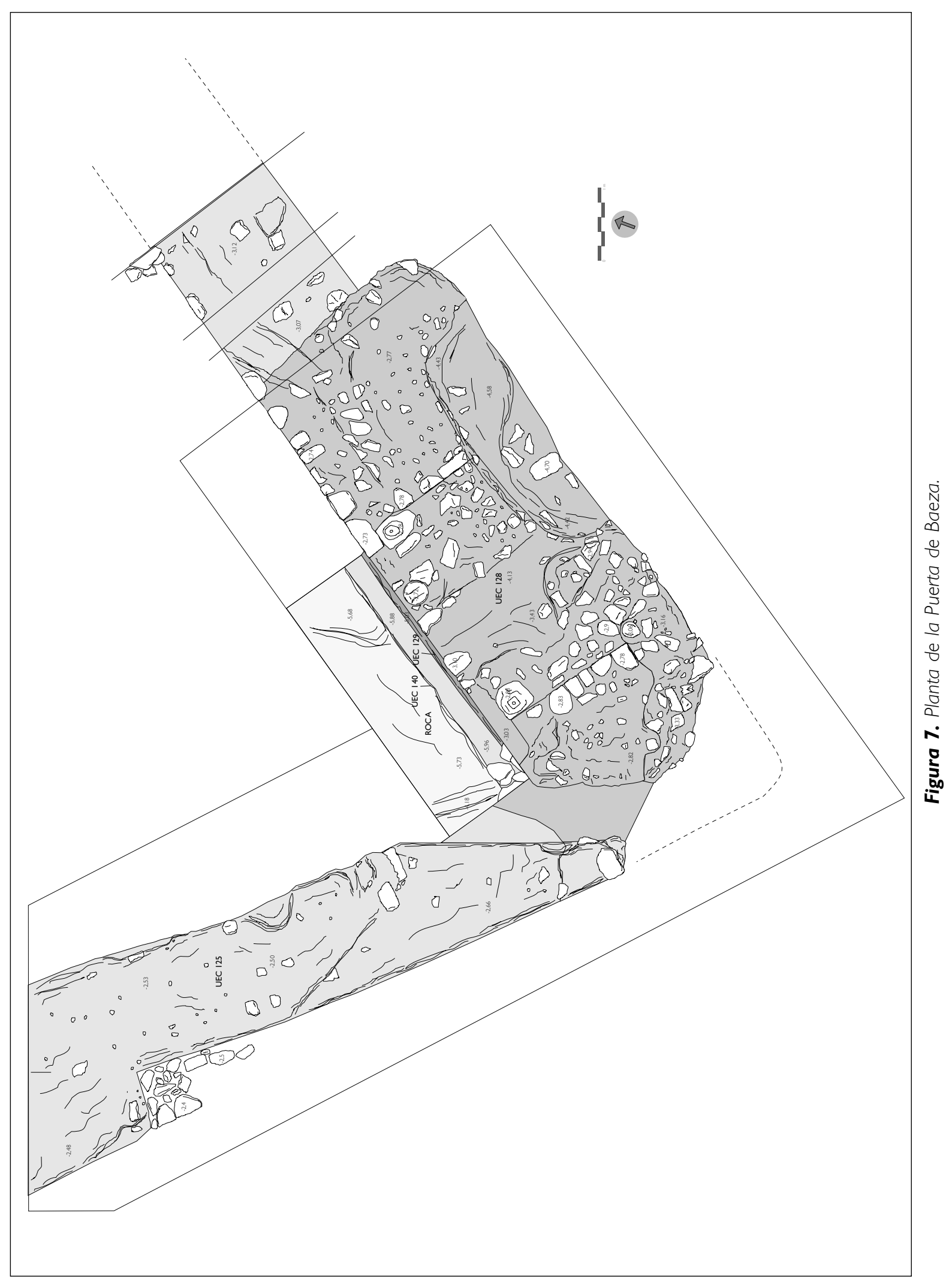




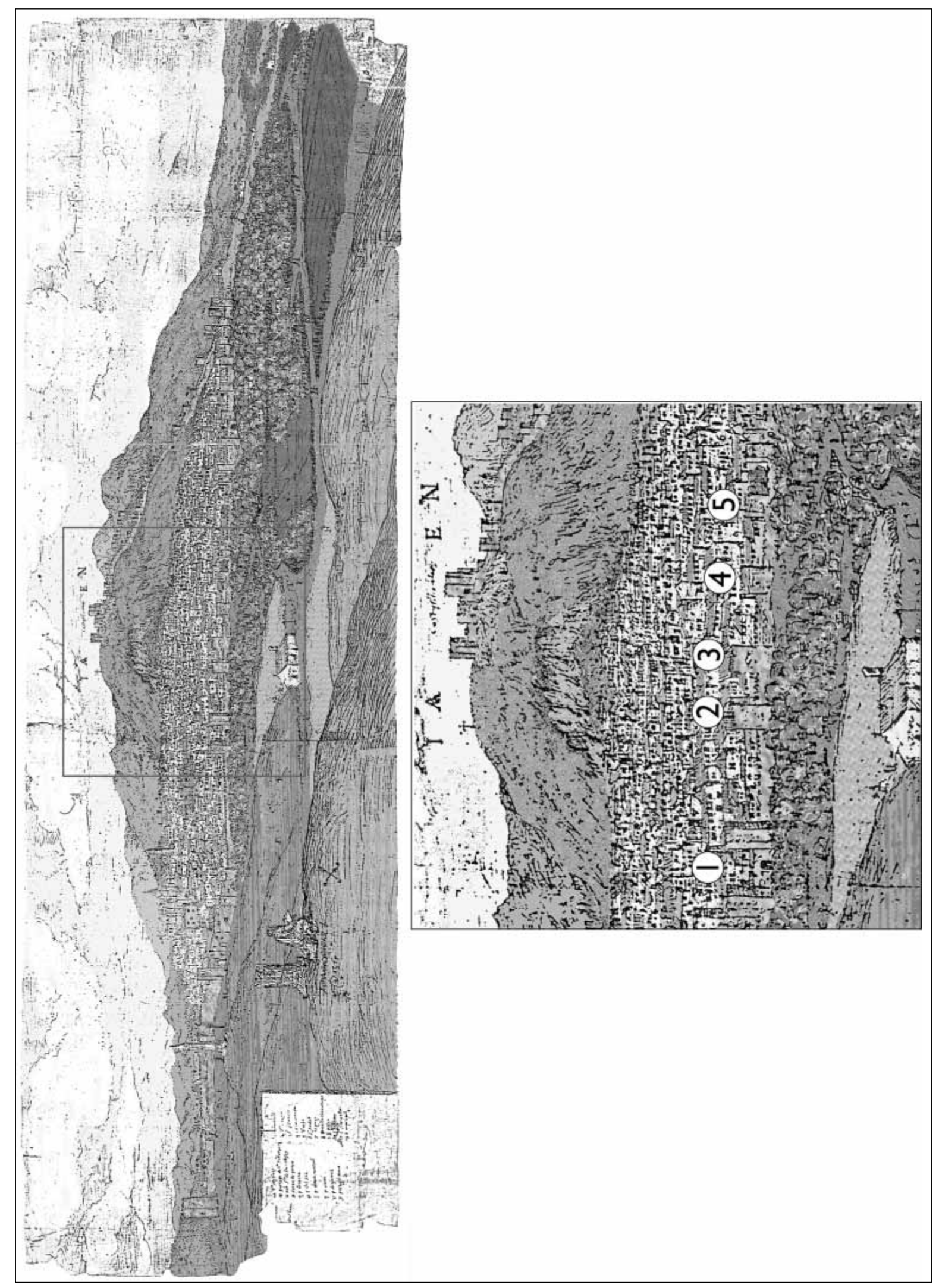

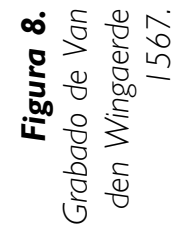




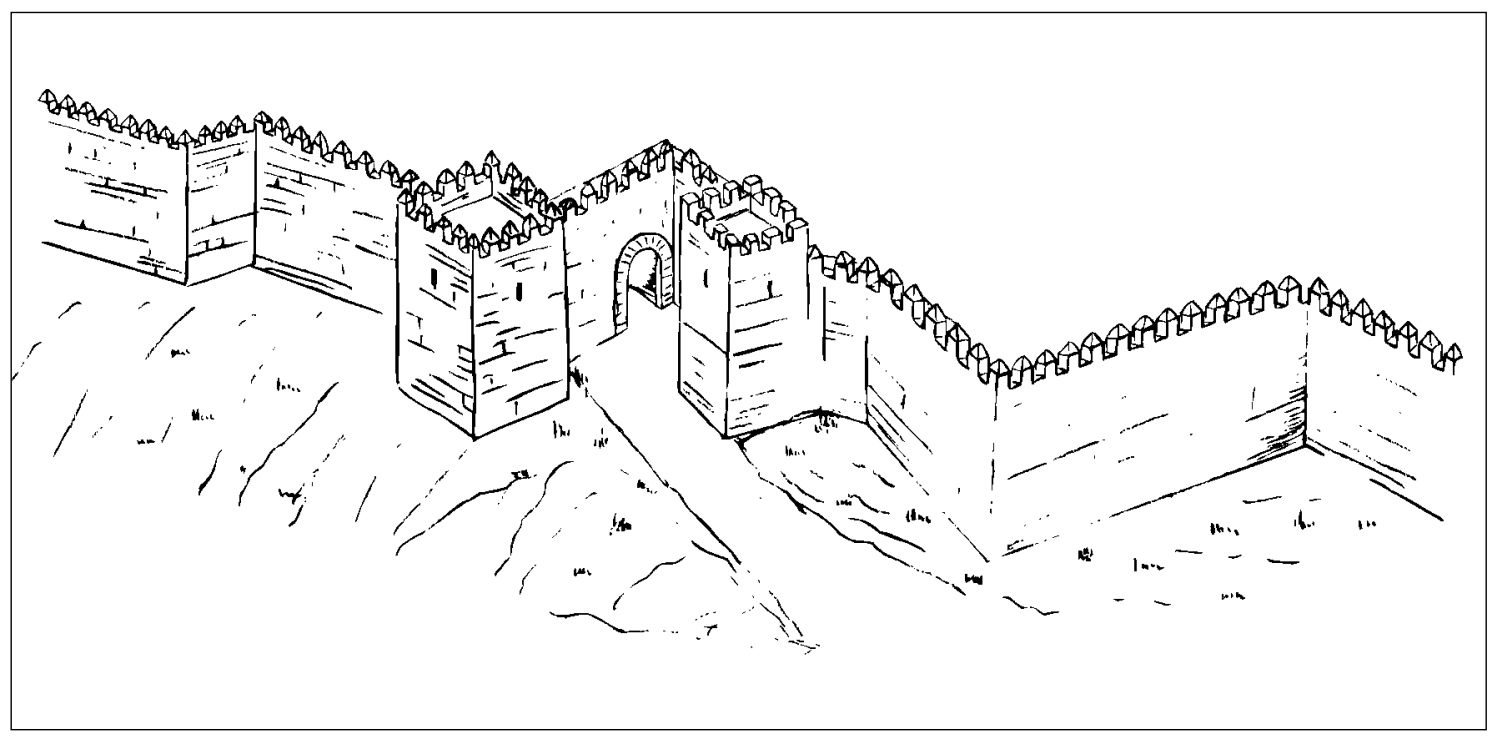

Figura 9. Reconstrucción idealizada de la Puerta de Baeza.

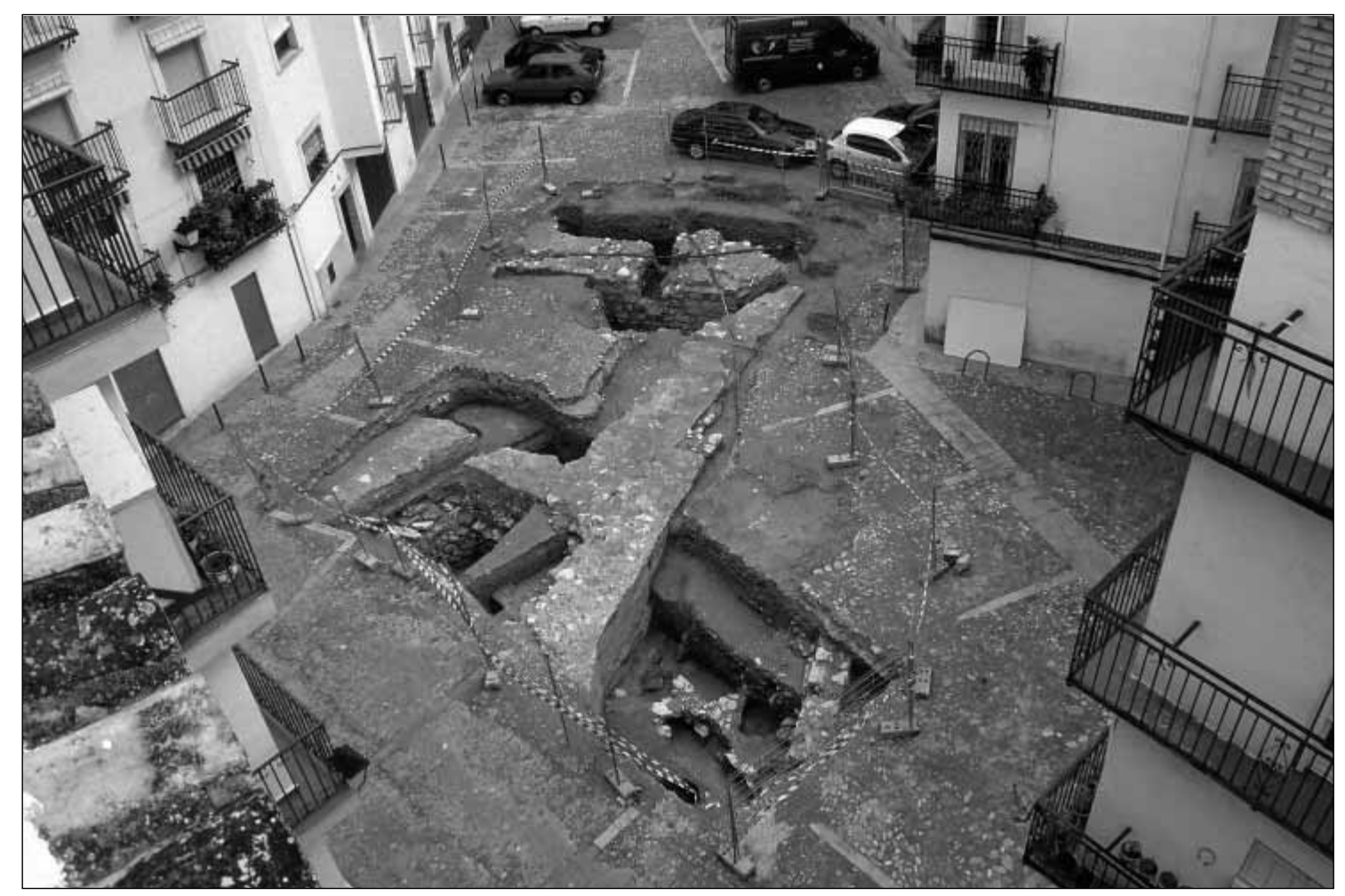

Lámina I. Vista general de la intervención. 


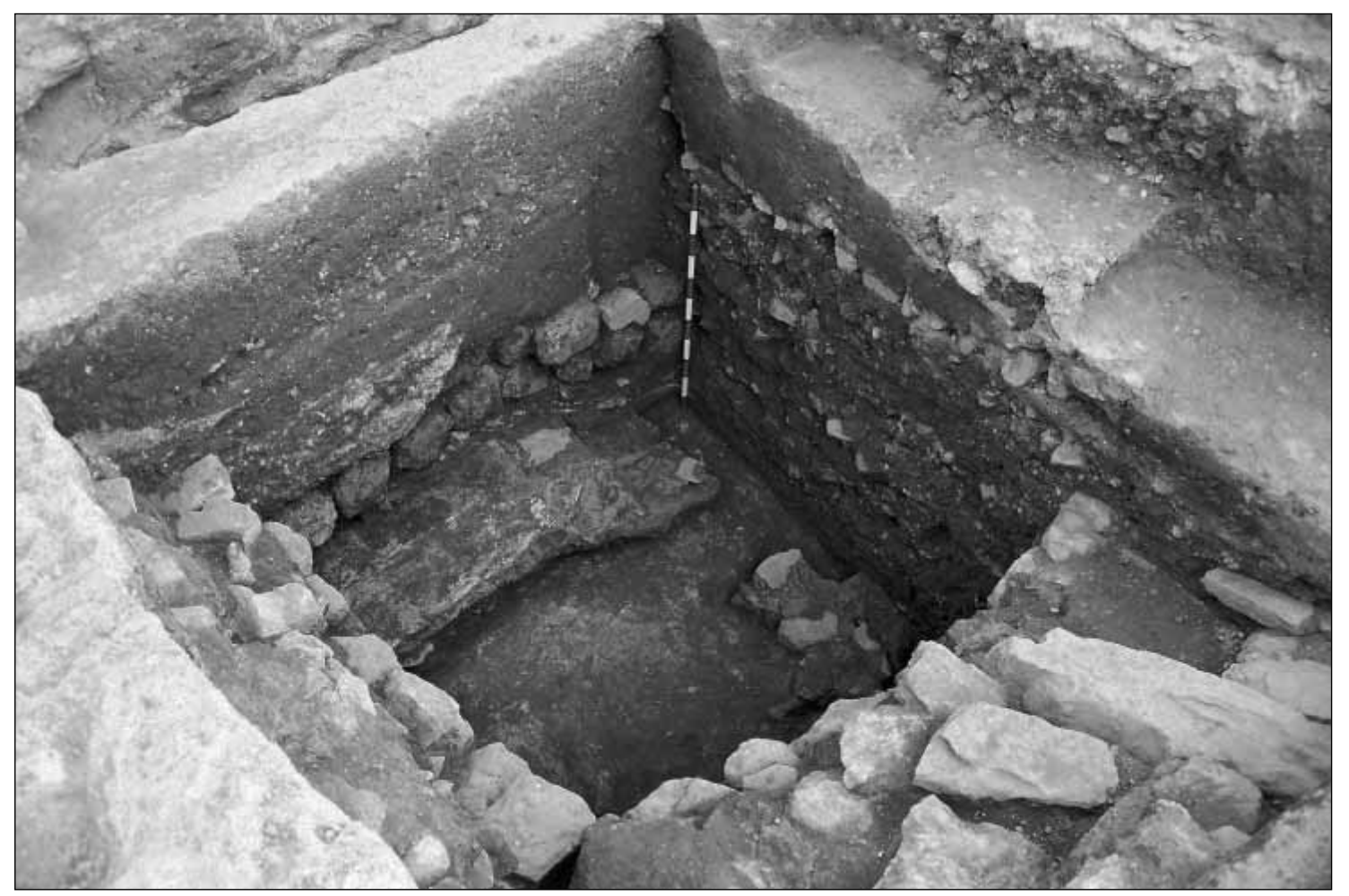

Lámina 2. Pavimento de mármol.

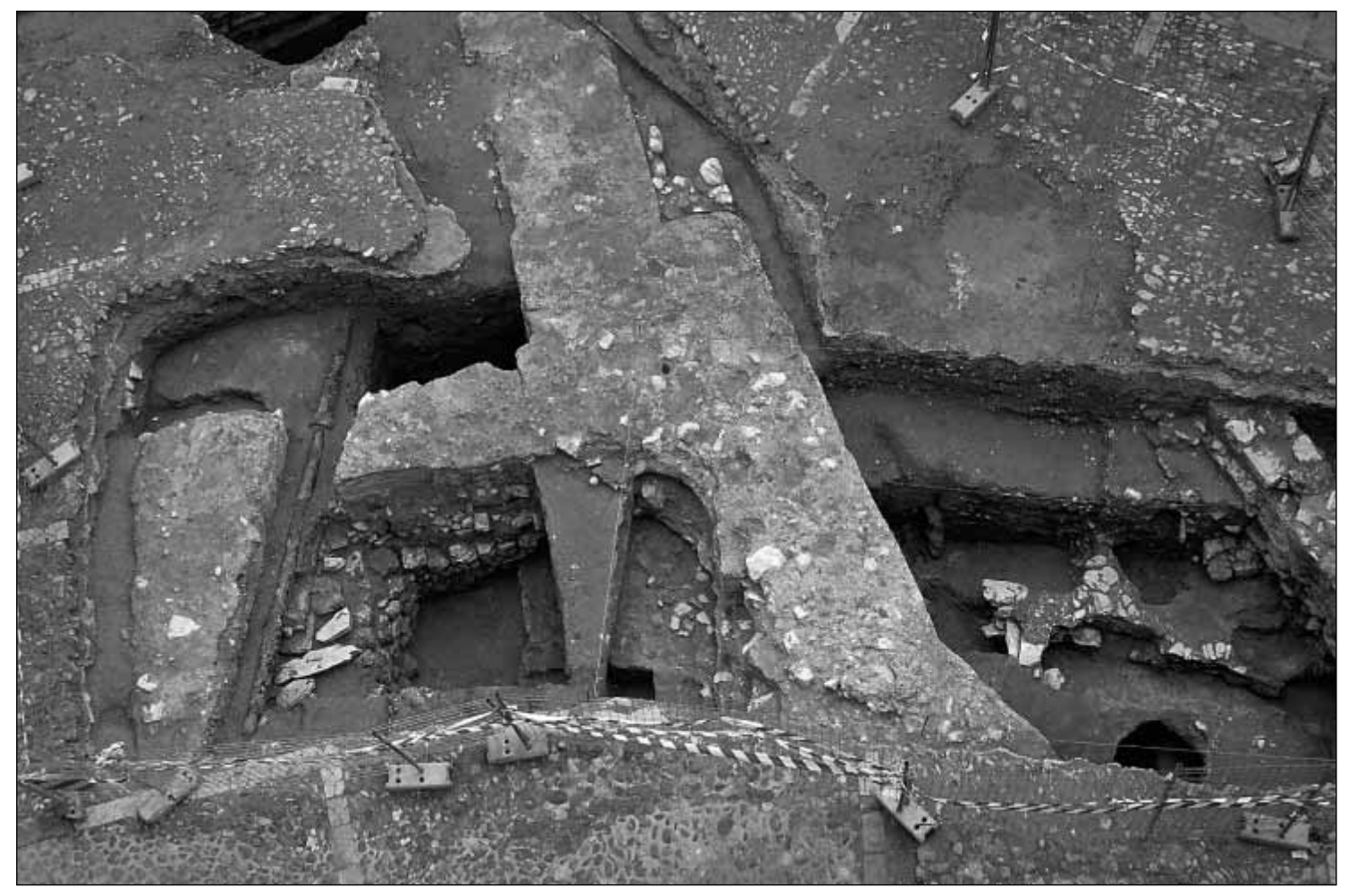

Lámina 3. Torre excavada. 


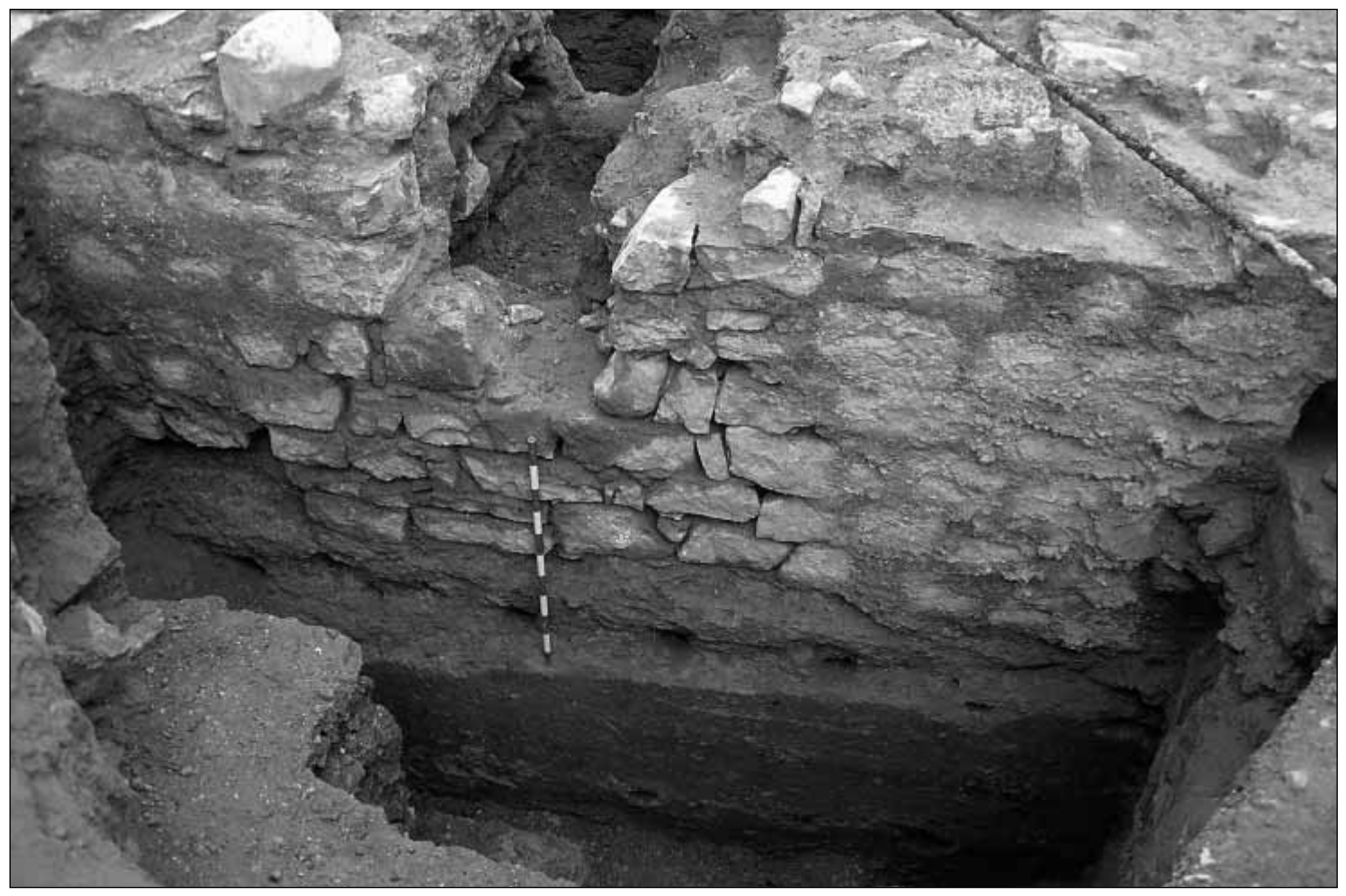

Lámina 4. Superposición de muralla de tabiyya islámica y de mampostería castellana.

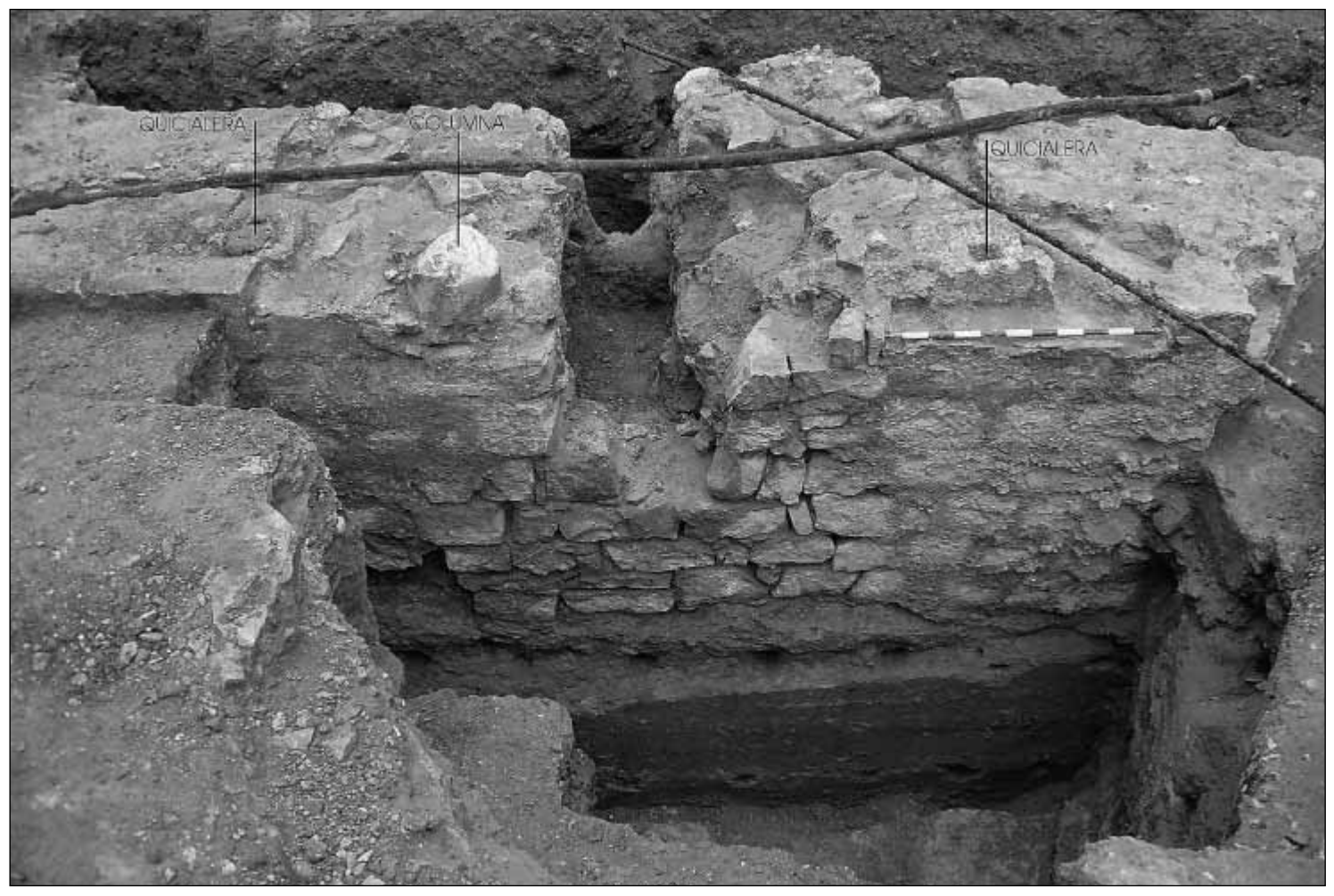

Lámina 5. Puerta de entrada a la ciudad medieval. 


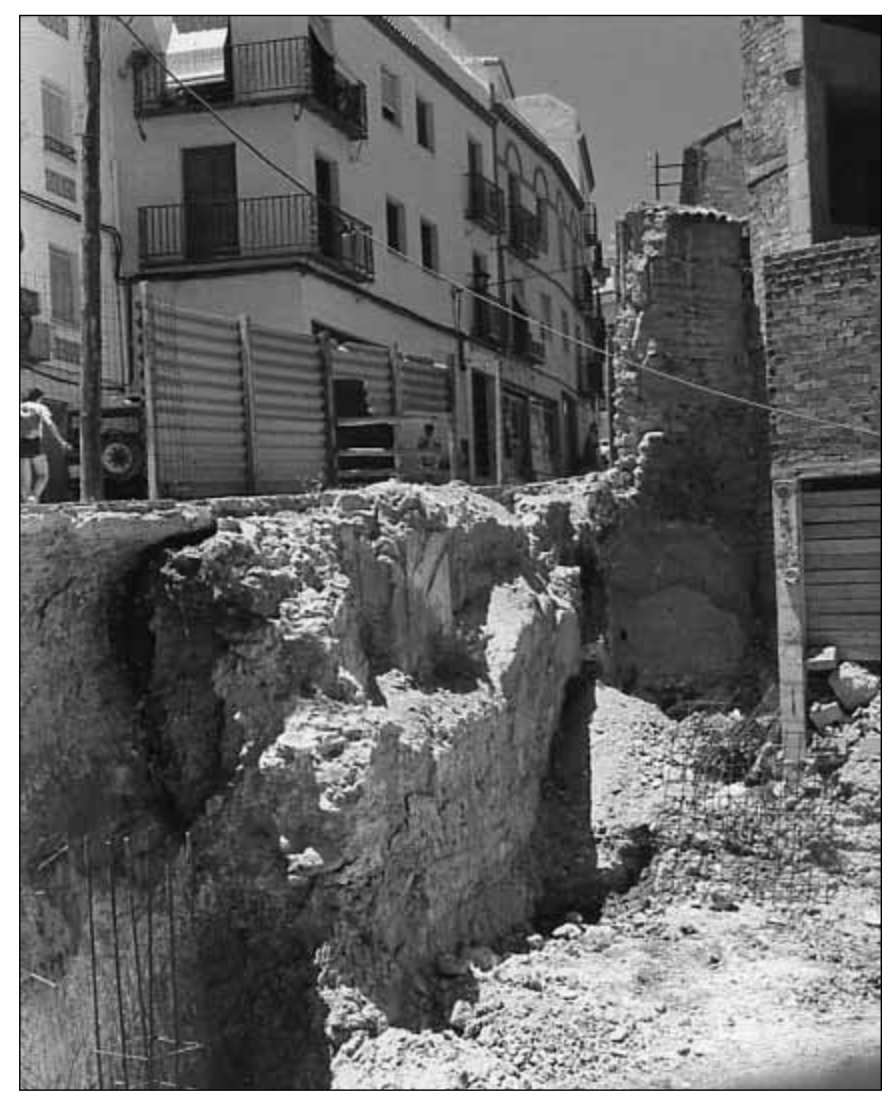

Lámina 6. Puerta que se realizó en el

siglo XVII en la Calle S. Andrés. Foto cedida por J. Ureña Castro.

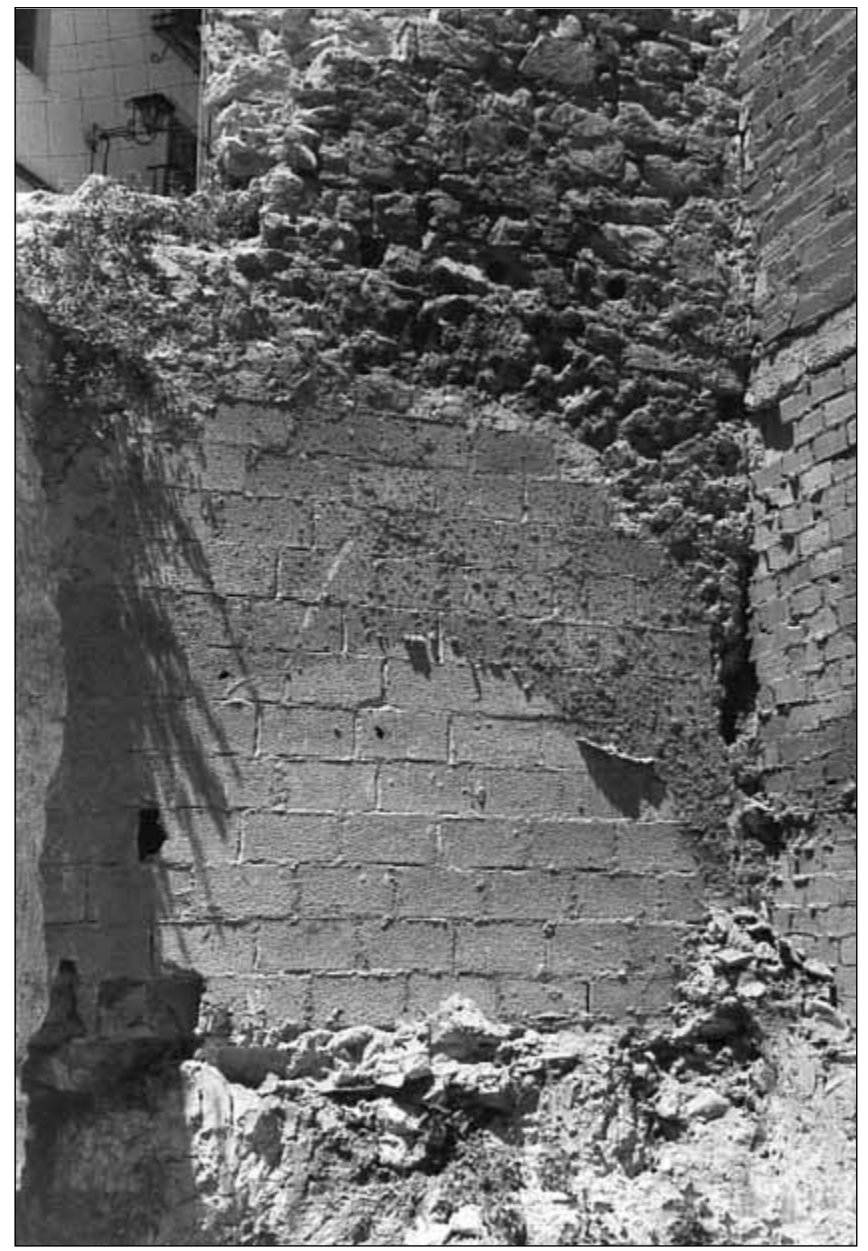

Lámina 7. Detalle de la puerta en la Calle S. Andrés. Foto cedida por J. Ureña Castro. 